Review Article

\title{
The role of the spatially fractionated radiation therapy in the management of advanced bulky tumors
}

\author{
Farshid MAHMOUDI ${ }^{a}$, Daryoush SHAHBAZI-GAHROUE|a, ${ }^{a}$, Nahid CHEGENI ${ }^{b}$ \\ ${ }^{a}$ Dept. of Medical Physics, School of Medicine, Isfahan University of Medical Sciences, Isfahan, Iran \\ ${ }^{b}$ Faculty of Medicine, Ahvaz, Jundishapur University of Medical Sciences, Ahvaz, Iran \\ *E-mail address: shahbazi24@yahoo.com,shahbazi@med.mui.ac.ir
}

\begin{abstract}
Spatially fractionated radiation therapy (SFRT) refers to the delivery of a single large dose of radiation within the target volume in a heterogeneous pattern using either a custom GRID block, multileaf collimators, and virtual methods such as helical tomotherapy or synchrotron-based microbeams. The potential impact of this technique on the regression of bulky deep-seated tumors that do not respond well to conventional radiotherapy has been remarkable. To date, a large number of patients have been treated using the SFRT techniques. However, there are yet many technical and medical challenges that have limited their routine use to a handful of clinics, most commonly for palliative intent. There is also a poor understanding of the biological mechanisms underlying the clinical efficacy of this approach. In this article, the methods of SFRT delivery together with its potential biological mechanisms are presented. Furthermore, technical challenges and clinical achievements along with the radiobiological models used to evaluate the efficacy and safety of SFRT are highlighted.
\end{abstract}

Key words: spatially fractionated radiation therapy (SFRT); GRID therapy; bystander effect; radiotherapy; bulky tumor.

\section{Introduction}

Most radiation therapy treatment plans are currently based on the delivery of a large uniform radiation dose to the tumor volume with lower exposure to the surrounding normal tissues with the goal of reducing normal tissue side effects, and improving local control. However, it was found that in some cases like hypoxic or bulky resistant deep-seated tumors the overall response to the conventional treatments is limited by toxicity to normal tissues. ${ }^{1-3}$

Spatially fractionated radiotherapy (SFRT) is a method that has been introduced to overcome limitations of acute and late normal tissue tolerance. There are many potential advantages of SFRT over conventional approaches in the treatment of deepseated and bulky tumors, as well as tumors that are inherently radio-resistant or grow quickly during treatment. In this technique, an atypical heterogeneous peak and valley pattern of the dose is distributed in a single fraction to the treatment volume. Unlike conformal methods, only a fraction of tumor volume is irradiated by primary beam, and the other fraction receives only scattered radiation. ${ }^{4,5}$ It may be combined with other modalities such as dose-time fractionation schemes, chemotherapy, and surgery to improve local control and to shorten the treatment course. ${ }^{6}$
SFRT is not a new concept. GRID therapy is the first method of SFRT that had initially been used to make smaller bulky tumors with minimal skin toxicity in the orthovoltage era. Nowadays, the principles of GRID therapy have been adapted with the advanced radiotherapy approaches, ${ }^{7,8}$ and several new techniques such as MLC-based GRID, virtual GRID and synchrotron-based microbeams have been suggested to produce GRID pattern.

This review article aimed to stimulate further research and discussion about the use of SFRT to clarify its radiobiological mechanisms and to specify ideal dosimetric parameters that lead to the highest therapeutic gain. To this end, the methods of SFRT delivery along with the potential biological mechanisms underlying the clinical efficacy of it and radiobiological models used to evaluate the efficacy and safety of GRID therapy are presented. The technical challenges and the clinical achievements in SFRT are also highlighted. 


\section{Types of SFRT/pros and cons}

From the technical point of view, several methods have been used clinically to deliver SFRT, each one having advantages and drawbacks.

\section{a) Block-based GRID therapy}

Blocked-based GRID therapy is the first approach of mega voltage (MV) SFRT that employs a broad beam passing through evenly spaced holes cast in a high-attenuation (Cerrobend or brass) block (Figure 1).

Early clinical studies with GRID therapy were obtained by a prototype GRID block. This block was made by casting melted Cerrobend liquid into a mold with several copper tubes. ${ }^{7,9-12}$ This configuration was an adaptation of the GRID used in the orthovoltage era. Several adaptions grew over time to improve the dosimetric properties of the GRID. In 2004, Zwicker et al ${ }^{13}$ constructed a new cerrobend GRID block consists of a hexagonal pattern of divergent circular holes with an effective hole diameter of $1.3 \mathrm{~cm}$ and a center-to-center separation of 1.8 $\mathrm{cm}$. With this configuration, a 1:1 ratio of open to the blocked area was achieved. Subsequent block-based GRID studies used a similar GRID design with different material, holes diameter, and holes separation to reduce block weight ${ }^{14}$ and to achieve higher therapeutic efficacy. ${ }^{12,14}$

Despite the initial success and promise, only a small number of institutions practice block-based GRID therapy today due to some technical challenges. These include: (a) GRID blocks are heavy ( 20 kg), and mounting and dismounting of them is difficult; (b) conventional GRID blocks have a limited number of holes. Indeed, the hole diameter and center-to-center distance between them is fixed. So, the shape and size of tumors and normal tissues are not considered; (c) since the tray to surface distance is not equal in all LINACs, it is necessary to build a dedicated block for each type of machine; (d) it is difficult to make holes of GRID so that the central axis and inner wall of them follow the divergence of the beam accurately; (e) since block-based GRID therapy uses single static field and because the absorbed dose decreases rapidly with depth, it is likely that the maximum dose is located outside the intended target for deep-seated tumors; (f) it is a challenge to put GRID blocks into the treatment planning system (TPS) to generate dose-volume histograms (DVHs).

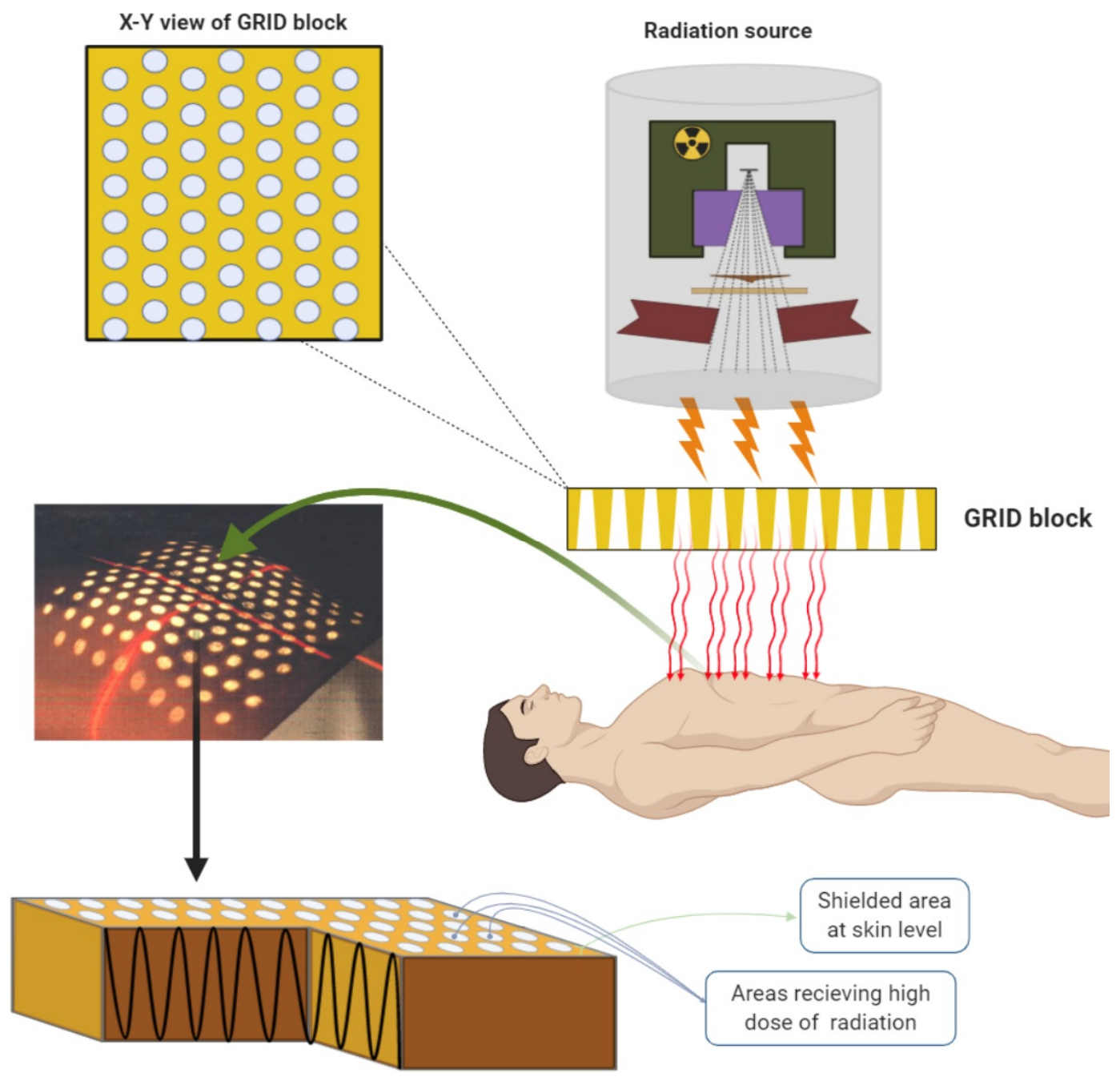

Figure 1. X-rays beam passing through the holes of the GRID block results in rounded footprints of dose in the tissue. Note the repeating pattern of valleys and peaks in beam profile from the block-based GRID therapy 


\section{b) MLC-based GRID therapy}

The block-based method demonstrated the clinical usefulness of GRID therapy, however, due to the mentioned deficiencies, the need for a cost-effective and more efficient approach to produce customizable GRID patterns was being felt. Ha et al ${ }^{15}$ proposed multi-leaf collimators (MLC) instead of physical GRID blocks to produce spatially modulated GRID beams.

The feasibility of MLCs for SFRT has been demonstrated by many authors. ${ }^{4,16}$ Clinical data demonstrate that the MLC-based GRID therapy is a safe modality that can achieve similarly and even potentially better treatment outcomes than the block-based method due to normal structure considerations. ${ }^{16}$ The MLCbased GRID therapy has many advantages over the block-based GRID, including (a) the modulated GRID fields can be produced easily and quickly by simply programming the leaf positions using a commercial TPS; (b) the hole size and hole separation can be easily changed for various tumors with different shape and size; (c) MLCs are common and well-understood devices and already available in most LINAC and would enable many institutions to start GRID therapy without significant hardware upgrades or modifications; (d) do not need to construct and handle bulky blocks; (e) it is cost-effective; (f) it allows for easy dose calculation within TPS, and hence radiation oncologists can examine dose distribution on CT images before treatment. ${ }^{15}$ Anyway, the MLC-based method requires a sequence of segments to cover the entire treatment field, which leads to a higher number of monitor units (MU) compared to the GRID block. The increased MUs have a direct impact on the surface dose and radiation leakage through the MLCs to the shielded area. Larger leaf size to construct a similar hole size compared to the GRID block and longer time for both the dosimetry and the treatment are the other drawbacks of the MLC-based method. ${ }^{15}$

Dose-delivery time seems to be more challenging for mobile tumors such as those in the thorax and abdomen than static tumors, such as those in the head and neck. As treatment time increases, it is more likely to degrade the valley to peak dose due to organ motion. This may adversely affect clinical outcomes. ${ }^{17}$

\section{c) Hybrid collimation system}

As discussed in the previous section, prolonged delivery time was the main drawback of the MLC-based method and could be prohibitive in practice, especially for mobile tumors and large fields. On the other hand, one of the most important drawbacks of the block-based method was the need for the construction and handling of dedicated and heavy blocks. To overcome these drawbacks, some authors ${ }^{18,19}$ proposed a unique hybrid collimation system as a time and cost-effective method to obtain the GRID pattern. This system generates a grid of square beamlets by the combination of two perpendicular sets of equally spaced leaves. One set is defined by the leaves of the MLCs, and the other by an in-house made cerrobend bars inserted in the LINAC head. While this orthogonal GRID pattern results in shorter treatment times and lower monitor units than the MLC and lower weight than the commercial GRID block ${ }^{14}$ $(15.8 \mathrm{~kg}$ vs $11.4 \mathrm{~kg})$, such devices are not available in most institutions.

\section{d) Virtual SFRT}

Recently, a novel virtual method of SFRT using helical tomotherapy (HT-GRID or TOMOGRID) was developed by Zhang et al. ${ }^{20,21}$ This approach allows treating patients by generating a patient-specific virtual GRID field using in-house software and IMRT delivery technique. In this approach, the number of holes along with hole size and hole spacing can be customized to treat the patients more effective than the physical GRID block. As discussed, there is very little control of the location of the maximum dose in conventional GRID therapy, because only one single static field is used typically. Alternatively, it has been shown that HT-GRID treatments can distribute the maximum dose within the treatment volume, especially for deep-seated tumors with large skin-to-tumor distance, and also can reduce the maximum dose to the normal tissue. Nevertheless, it has a higher valley to peak dose ratio compared to conventional GRID methods and also has a long beam-on time which is of concern due to potential tumor motion. $^{22}$

\section{e) Lattice radiotherapy}

The shortcoming of two-dimensional (2D) SFRT is that a considerable amount of peripheral and superficial tissue that is not involved in the clinical target volume is inevitably exposed to a high dose of radiation. To decrease the dose in normal tissues, Wu et $\mathrm{al}^{23}$ described a modern type of SFRT, called three-dimensional (3D) lattice radiotherapy (LRT). This new technique is based on the 2D GRID therapy and the new advances in radiation delivery techniques, such as IMRT, VMAT, and robot-driven converging beams. Lattice radiotherapy creates multiple localized high dose regions (sphere-like vertices) within the tumor volume with a certain degree of separation to form lower dose regions. Normal tissue outside of target volume will spare against high dose. The difference between the 3D lattice and conventional 2D GRID irradiations is shown in Figure 2.

Clinical results of LRT show promise for the future. ${ }^{24,25}$ However, such a 3D SFRT approach may not lead to optimal dose distribution; because the large number of small-field beams that focus inside the target inevitably overlap with each other and increase the valley to peak dose ratio. To overcome this problem, Jin et $\mathrm{al}^{26}$ present a different 3D SFRT method based on MLCs that uses multiple beams from different gantry angles. This method has the characteristics of both 3D-conformal radiotherapy and GRID therapy. This technique differs from the MLC-based GRID therapy which uses only 

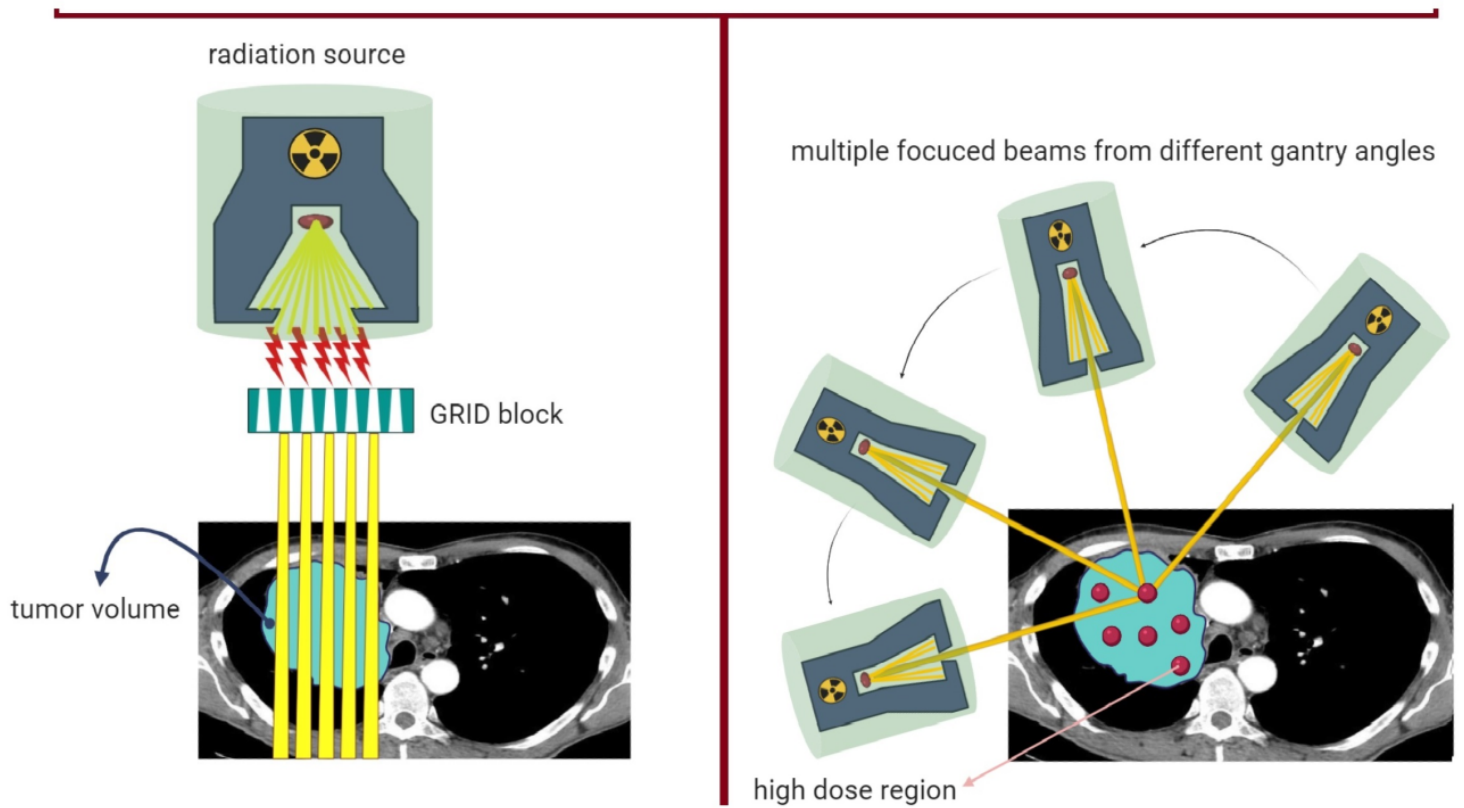

Figure 2. Conceptual representation of the comparison between the conventional 2D GRID and the 3D lattice irradiations ${ }^{23}$

Table 1. Technical challenges and advantages of various types of SFRT techniques,

\begin{tabular}{|c|c|c|}
\hline Method & Advantage & Drawback \\
\hline $\begin{array}{l}\text { Block-based } \\
\text { GRID therapy }\end{array}$ & $\begin{array}{l}\text { Reusable } \\
\text { Adjustable field by closing jaws } \\
\text { Saving time for both the dosimetry planning ( } 10 \\
\text { minutes vs. } 2 \text { hours for MLC by a skilled dosimetrist) } \\
\text { and the treatment ( } 5 \text { minutes vs. } 20 \text { minutes for MLC) }\end{array}$ & $\begin{array}{l}\text { The need for handling heavy blocks } \\
\text { Limited ability to customize GRID plans } \\
\text { Limited ability to shape the 3-D dose distribution } \\
\text { Having only a limited number of holes } \\
\text { Putting GRID collimators into TPS is challenging } \\
\text { Concerns about the activation of the GRID block }\end{array}$ \\
\hline $\begin{array}{l}\text { MLC-based } \\
\text { GRID therapy }\end{array}$ & $\begin{array}{l}\text { Found in most institutions } \\
\text { Easy to plan } \\
\text { Cost-effective } \\
\text { Easy dose calculation within TPS } \\
\text { Flexible in field shaping } \\
\text { Delivering more conformal dose to the targets }\end{array}$ & $\begin{array}{l}\text { Longer delivery and dosimetry times than GRID block } \\
\text { Requires more monitor units } \\
\text { Larger penumbra width along the leaf-motion direction } \\
\text { Intra- and inter-leaf radiation leakage } \\
\text { Higher surface doses } \\
\text { Larger leaf size is needed to construct a similar hole size compared to a GRID block } \\
\text { Less effective in mobile tumors treatment }\end{array}$ \\
\hline $\begin{array}{c}\text { Hybrid } \\
\text { collimation } \\
\text { system }\end{array}$ & $\begin{array}{l}\text { More efficient delivery than GRID blocks } \\
\text { Easier to craft } \\
\text { Lighter than conventional GRID blocks } \\
\text { Faster than the MLC-based method }\end{array}$ & $\begin{array}{l}\text { Less effective in customizing GRID patterns } \\
\text { Inequality of valley to peak dose ratio along diagonal direction compared to principal axes } \\
\text { Difficulty in creating a set of leaves that follows the beam divergence } \\
\text { Limited availability in most institutions }\end{array}$ \\
\hline Virtual SFRT & $\begin{array}{l}\text { Controlling the location of the maximum dose } \\
\text { More efficient in treating deep-seated tumors } \\
\text { More efficient in sparing the critical organ at risk } \\
\text { A customizable patient-specific designed template }\end{array}$ & $\begin{array}{l}\text { Long beam-on time and concern about motion } \\
\text { Limited access to the advanced radiotherapy equipment } \\
\text { Increasing the valley to peak dose ratio compared to conventional methods } \\
\text { Difficulty in planning }\end{array}$ \\
\hline $\begin{array}{l}\text { Lattice } \\
\text { radiotherapy }\end{array}$ & $\begin{array}{l}\text { More efficient in sparing superficial tissues } \\
\text { 3-D dose distribution }\end{array}$ & $\begin{array}{l}\text { Overlapping of small-field beams with each other } \\
\text { Higher valley to peak dose ratio than block-based GRID } \\
\text { Limited access to the advanced radiotherapy equipment } \\
\text { Long treatment time }\end{array}$ \\
\hline MRT & $\begin{array}{l}\text { Very sharp dose fall-off } \\
\text { Sharp penumbra at any depth } \\
\text { Larger peak dose } \\
\text { Very short irradiation time } \\
\text { Very low divergent beam }\end{array}$ & $\begin{array}{l}\text { Dose distribution sensitivity to the organ motion } \\
\text { Need for a precise patient-positioning system } \\
\text { Need for a robust position marker system } \\
\text { Limited availability of delivery facilities }\end{array}$ \\
\hline
\end{tabular}


one field and also differs from the 3D LRT; because it uses the beams only at the special directions to limit their overlaps. In this condition, the characteristic of GRID therapy, represented by the valley to peak dose ratio, would not degrade with increasing the number of lattice spheres.

\section{f) Microbeam radiation therapy}

Microbeam radiation therapy (MRT) has moved the GRID concept to the microscopic level. This is an innovative type of SFRT using a synchrotron-generated narrow beam of radiation with widths of 25 to $50 \mu \mathrm{m}$. The separation between the high and low-dose regions is around 200 to $400 \mu \mathrm{m}$. Typically, MRT uses arrays of quasi-parallel low energy (50 to $300 \mathrm{keV}$ ) microbeams to deliver an extremely high peak dose of several hundred Gy at very high dose rates. ${ }^{27,28}$

The narrow micro-planar beam with minimal divergence achieves a higher and sharper dose deposition throughout the target. Since the scattering effect is less in the lower energy range, kilovoltage beams allowing a sharp dose fall-off even at the depth of target volume. The low energy of monochromatic beams makes them suitable to treat shallow targets in the brain. However, deep-seated targets can also be treated using imageguided MRT that uses several ports. ${ }^{27,29}$

Typical in-beam doses in MRT are more than one order of magnitude greater than those delivered in the macroscopic GRID therapy. It is postulated that such high doses can kill tumor cells selectively. Since the high delivered dose is fractionated in small volumes and only a small fraction of tissue receives primary radiation, it can be well tolerated by normal tissue. ${ }^{29,30}$

A very short irradiation time is required to prevent blurring of the peaks and valleys due to tissue motion. So, the irradiation must be done at a dose rate of $100 \mathrm{~Gy} \cdot \mathrm{s}^{-1}$ or higher to assure irradiation of the whole target volume in a second or fractions of seconds. ${ }^{27}$

The potential advantage of MRT has been demonstrated in several preclinical studies using small animals. ${ }^{29}$ Although encouraging, but it is still at the preclinical stage and has not yet been trialled in patients. Before moving to the clinical trial, MRT must be tested in larger animals to validate its feasibility and safety, and to find the most appropriate plans and dosimetric parameters for larger, deep-seated tumours. ${ }^{27,31,32}$

We summarize the main technical advantages and drawbacks of various types of SFRT in Table 1.

\section{GRID activation and photo-neutron contamination}

There is a constant concern about the photo-neutron contamination due to high-z material in the head of LINAC when using photon energy above $10 \mathrm{MeV} .^{38,39}$ This concern is more pronounced in the GRID therapy, which uses a highattenuation GRID block (a potential additional source of neutron contamination) and larger monitor units. Undesired photo-neutrons produced in the GRID block can cause an increase in the patient dose. On the other hand, the GRID blocks can also act as a shield against the neutrons generated in the LINAC head..$^{37,39}$

In a study, Wang et al. compared the neutron dose equivalent to the patient and staff who access the treatment room with and without a brass GRID block for an $18 \mathrm{MV}$ photon beam. They reported that the neutron dose equivalent to the patient in the presence of a GRID block is $35.3 \%$ lower than that obtained with the conventional open field with the same field size and MU. In addition, no significant difference was observed between the neutron dose equivalent at the entrance of the vault with and without the GRID block. ${ }^{37}$ Similar results were reported by Tajiki and coworkers. ${ }^{40}$ In the same vein, Chegeni et al. in their simulation study noted that the photo-neutron production in the head of a LINAC operated at $18 \mathrm{MV}$ is increased only by $0.3 \%$ with the GRID block. Although, the neutron doses in the tumor volume was about $60 \%$ lower than the conventional open field. ${ }^{36}$ This can be explained by the fact that a large amount of the neutron beam is absorbed by the GRID block.

Another concern is about the delayed activation of the GRID block. A long-time of irradiation with high-energy photon beams can cause the activation of the GRID block and deliver unwanted dose to the patient as well as radiation workers who is handling the blocks. Wang et al. measured radiation-activation exposure on the surface of the GRID block following a 2000 monitor unit exposure. The average half-life of the activation activity was $12 \mathrm{~min} .{ }^{37}$

Taken together, the results of these studies suggest that the GRID therapy is a safe treatment approach for deep-seated large tumors. Nonetheless, the possible risk of high exposures due to the activation of the GRID block must be considered. It has been recommended that a time interval should be considered between the GRID irradiation and handling the GRID block. ${ }^{36,37,40}$

\section{Radiobiologic rationale of SFRT}

Despite several available clinical publications and several hundred patients who have been treated by SFRT, the radiobiological mechanisms behind the success of SFRT remain incompletely understood. Nevertheless, some possible mechanisms involved in the differential effects of SFRT on tumor cell killing and normal tissue sparing have been proposed.

\section{a) Volume effect and normal tissue repair}

Unlike conventional radiotherapy, SFRT has been found to produce limited toxicity in normal tissues despite the large single delivered dose. This may relate to the so-called dosevolume effect. Experimental data from beam sizes in the order of micrometres to centimetres have shown that the tolerance doses for specific biological tissues rise when beam size reduces. ${ }^{29,30,41}$ 
Furthermore, GRID therapy takes advantage of the better repair capabilities of normal cells than tumor cells. It was found that when a small segment of skin and subcutaneous tissues is spared, such as by a GRID block, the non-irradiated cells can serve as regrowth centers for normal tissues, repair damaged areas and reduce the complications. ${ }^{42,43}$

\section{b) Bystander effect}

While dose distribution of the GRID therapy is highly nonuniform, and a fraction of tumor volume is spared from primary radiation, uniform tumor regression is observed clinically. ${ }^{4,44} \mathrm{It}$ has been speculated that "bystander effects" may play an important role in this uniform response. ${ }^{45}$ Bystander is the phenomenon in which unirradiated or partially irradiated cells experience effects such as DNA damage, gene expression, cell proliferation, apoptosis, and cell death in response to signals received from nearby irradiated cells. ${ }^{46}$

There are some indications that a high single non-uniform dose of GRID therapy can activate the molecular pathways leading to apoptosis, vascular damage, and modulation of the adaptive immune response. ${ }^{6,45}$ Data from an in vitro study of GRID therapy indicated that the unirradiated or partially irradiated cells in the shielded regions exhibit more cell death than that expected from exposure to only background valley dose. There was an increase in expression of genes involved in cell cycle arrest, DNA repair and apoptosis, and overexpression of antioxidant, heat shock, and chaperone genes in the nonirradiated cells following GRID irradiation. However, no statistically significant changes in the directly irradiated cells were reported. ${ }^{45}$

Besides the killing effects, it has been found that in some circumstances, the bystander effect may exert a protective impact on cells through the inhibition of toxic factors and the production of growth factors that encourage tissue regeneration. ${ }^{47,48}$ Transforming growth factor $\beta 1$ (TGF- $\beta 1$ ) is a multifunctional cytokine that is postulated to be involved in the protective response of the bystander effect after GRID irradiation. Following radiation therapy, the action of TGF- $\beta 1$ leads to the late normal tissue response that is manifested by fibrosis and connective tissue scarring. Down-regulation of TGF- $\beta 1$ in 34 patients treated by GRID therapy with a median dose of 15 Gy can be an index reflecting limited soft tissue toxicity and low risk of developing post-GRID therapy fibrosis. ${ }^{44,47}$

\section{c) Microvascular damage}

It has been shown that the unique dose distribution of GRID therapy results in acute induction of tumor necrosis factor $\alpha$ (TNF- $\alpha$ ), ceramide, and secretory sphingomyelinase (S-SMase) which can cause apoptosis, both in the epithelial and endothelial cells. ${ }^{45,47,49}$ Since each endothelial cell in tumor blood vessels supplies to a segment of a large number of tumor cells, killing them would result in initiating a cell death cascade in the whole tumor volume and lead to severe vascular damage.

Sathishkumar et $\mathrm{al}^{49}$ investigated the potential role of ceramide in tumor regression after GRID therapy. They measured the serum content of ceramide and S-Smase in 11 patients before and after the dose of $15 \mathrm{~Gy}$ and showed that the S-SMase activity and serum level of ceramide increase following GRID irradiation and correlate with the clinical response. In another study, the effect of a single dose of $20 \mathrm{~Gy}$ from LRT on endothelial cell growth was tested. Serum samples were obtained from mice with allogenic Lewis lung carcinoma tumors before and after LRT. Significant growth inhibition of endothelial cells was reported when grown in the serum collected from the mice treated with LRT compared to cells that were grown in the serum collected from either the unirradiated or uniform irradiated groups. These findings corroborated with elevation in the level of TNF- $\alpha$ and ASMase activity after LRT. ${ }^{50}$ Also, in the treatment of 34 patients with spatially fractionated (GRID) radiation therapy a strong correlation between complete clinical response and an increase in the basal level of TNF- $\alpha$ after SFRT was reported. ${ }^{47}$

\section{d) Immune system activation / abscopal effects}

Conventional radiotherapy is considered as a suppressor of the immune system due to the inherent sensitivity of lymphocytes to radiation, ${ }^{51}$ however some studies have demonstrated that high local single-dose of radiation such as used in GRID therapy can result in T-cell-mediated cytotoxicity against the tumors by altering the tumor microenvironment from that of immunesuppressive to immune-activating. ${ }^{52,53}$ Interestingly, this antitumor immune response is not limited to the irradiated cells or their immediate neighbors, but also the metastatic cells far from the irradiated site may be affected. This phenomenon is called the "abscopal effect". The abscopal effect is potentially important for anti-tumor response and is mediated by the immune system and/or the cytokines. ${ }^{50}$

The abscopal effect attributed to SFRT has been addressed in some studies. A lower metastasis rate was reported in the treatment of 53 patients with locally advanced (T4 or N3) squamous cell carcinoma (SCC) of the head and neck using GRID therapy compared to historical controls. ${ }^{54}$ In an investigation using an animal model, mice with lung adenocarcinoma xenograft tumors implanted in both right and left flanks were treated with spatially fractionated GRID radiation. It was observed that irradiating tumor cells in one flank using a single high dose of GRID therapy, would lead to an increase in the regression of the untreated tumor in the other flank. It was also reported that GRID therapy resulted in the induction of more pro-apoptotic factors and increased cell death in the unirradiated tumor compared to the uniform radiation field. This suggests that the GRID therapy can induce cytotoxic factors such as cytokines (TNF or TRAIL) which may cause an abscopal response in tumors far away from the irradiated 
region. ${ }^{55}$ Similar findings were reported in another study by Kanagavelu et al. ${ }^{50}$ They observed that irradiating the tumors implanted in the left flank of mice using LRT, can induce tumor growth delay in the right tumors through the abscopal effects. However, the uniform irradiation to the whole tumor was less effective in eliminating the right tumors. To investigate the potential role of the immune system activation in the observed abscopal effects, they measured serum level of cytokines (IFN$\gamma$, IL-2, IL-10 and IL-4) before and after of LRT. A significant increase in both IFN- $\gamma$ and IL-2 secretion along with the decreased levels of the IL-4 and IL-10 in the serum samples after LRT, indicated that LRT can induce a robust Th1 response. Th1 cells secrete cytokines interleukin-2 (IL-2) and interferon- $\gamma$ (IFN- $\gamma$ ) with the ability to induce T-cell dependent abscopal effects. Th1 secretion also can promote growth inhibition by suppressing the Th2 cells which secrete IL-4 and IL-10 with immunosuppressive activity. There was also an increase in CD3 infiltration in the unirradiated distant tumor cells, which is essential for anti-tumor immune response. These findings suggest that the cell-mediated immune responses might play a role in SFRT-triggered abscopal effects. ${ }^{50}$

A schematic presentation of the potential role of the bystander/abscopal effects as well as activation of the immune system in tumor response following spatially fractionated irradiation is illustrated in Figure 3.

\section{e) Re-oxygenation}

Hypoxic tumors have been found to be resistant to conventional radiotherapy. However, it has been speculated that a large number of tumor cells, both oxygenated and hypoxic, are killed by a high single dose to the open regions of GRID fields. Thereby, the residual hypoxic tumor cells would become reoxygenated following SFRT. In this condition, the tumor response is expected to improve during the subsequent conventional radiotherapy after SFRT. ${ }^{7,56}$

These may not be the only pathways that could explain how GRID works, and more investigations are needed to clarify the biological mechanisms.

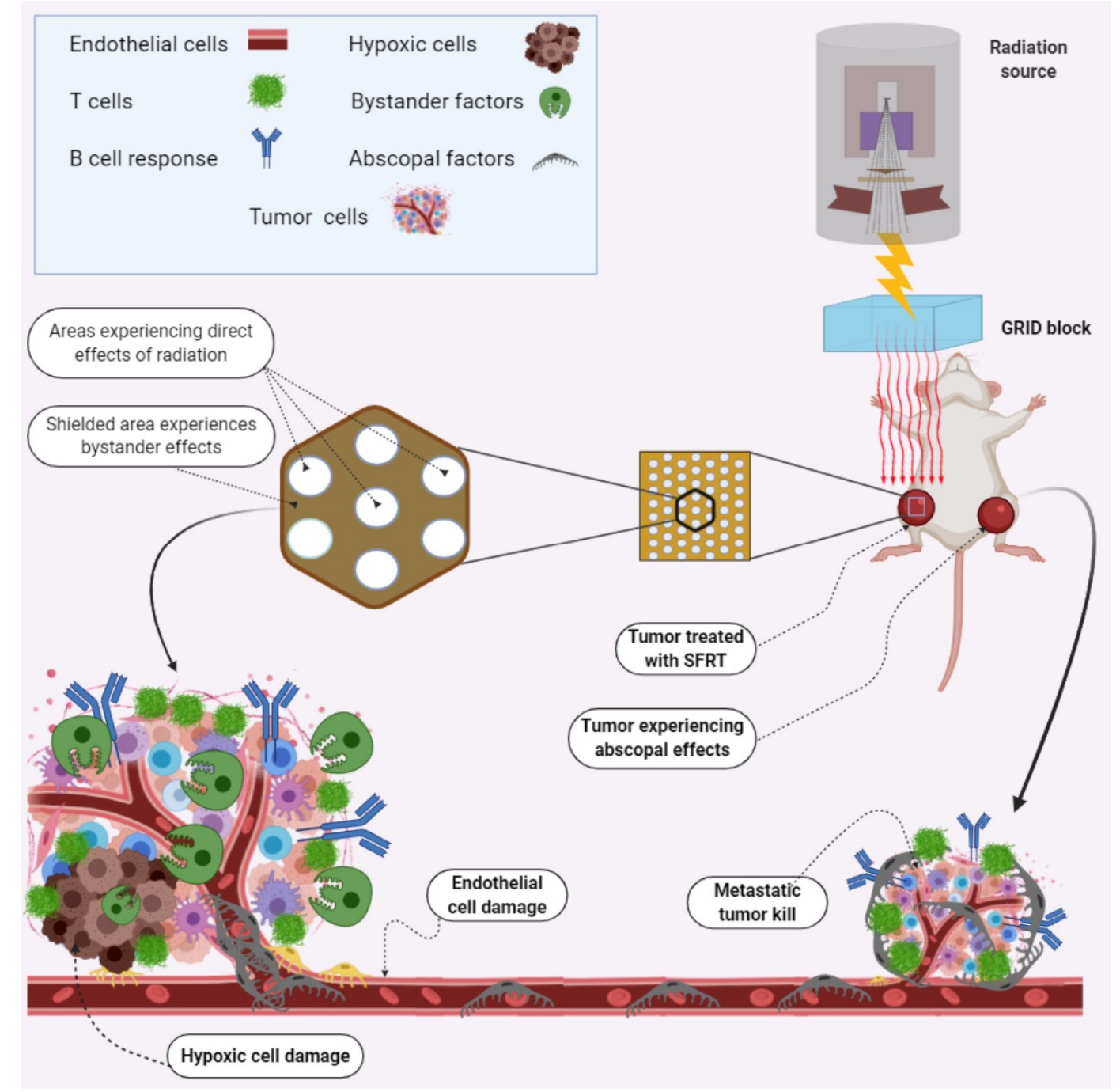

Figure 3. Cell killing within the irradiated and distant tumors from bystander/abscopal effects induced by GRID irradiation 


\section{EBRT following GRID therapy}

It has been shown clinically that the conventional EBRT given after GRID therapy resulted in better tumor response than GRID therapy alone. $7,10,11,16$

Although more normal cells would be spared in SFRT than in conventional radiation fields, the effective dose delivered by GRID therapy alone may be insufficient to achieve complete tumor control. Thereby, a course of the conventional EBRT may be needed to fully control tumor growth after GRID therapy. ${ }^{7,44}$

Conventional EBRT synergizes with SFRT to drive tumor regression. ${ }^{57}$ As discussed earlier, SFRT probably improves EBRT outcomes through reoxygenation. ${ }^{56}$ On the other hand, it has been shown that the subsequent EBRT after SFRT can amplify the abscopal effect of the SFRT and improves the tumor response. ${ }^{55}$

\section{Clinical results}

Despite all limitations, a large number of patients with various tumor histology have been treated by SFRT in recent years for not only shallow tumors, such as head and neck, skin, extremities, and breast, but also deep-seated bulky tumors, such as lung, liver, abdomen, and pelvis for either palliative or curative intent.

In 1990, for the first time, Mohiuddin et $\mathrm{al}^{9}$ reported the clinical success with GRID therapy in treating 22 patients with sarcomas, recurrent gastrointestinal cancer, massive liver metastases, and miscellaneous tumors. All patients were symptomatic and had not responded to the prior conventional radiotherapy, surgery, and chemotherapy. A GRID block with a 1:1 ratio of open to blocked area was used to deliver a prescribed single dose of 1000 to 1500 cGy to the open area. 14 patients were given external beam radiation therapy (EBRT) in addition to the GRID treatment. The overall response rate was $91 \%(64 \%$ : palliation of symptoms and 27\%: complete resolution of disease) with no acute side effects in $82 \%$ and no long-term complications in $100 \%$ of patients. These impressive results were the motivation for doing the next work in 1996; in which 61 patients with sarcomas, SCC, melanoma and adenocarcinoma were evaluated for normal tissue morbidity and palliative response to GRID therapy with a single dose of 1000-2500 cGy. ${ }^{10}$ Data revealed an overall response rate of $91 \%$ with no significant acute morbidity. However, when the GRID doses of $\geq 1500$ cGy were used, the overall response rate increased to $100 \%$. These results accord with the study of Mohiuddin et al. (1996 and 2002) and Neuner et al. (2012) that also represented a dose-dependent relationship between GRID treatment and clinical response. ${ }^{7,11,16}$

Furthermore, patients were followed-up for 1-28 months with a median of four months. One of the most common limitations of GRID studies is the short follow-up time due to the short life expectancy of some patients and their end-stage disease. Among eight patients who were followed 12 to 28 months, no one showed late morbidity. The complete response for patients who received concurrent EBRT was higher than that seen in patients treated with GRID therapy alone. ${ }^{10}$ This finding is consistent with other clinical studies, which showed that the complete response rate increased when the external radiation dose was added to the GRID therapy. ${ }^{7,11,16}$ However, the combination of additional EBRT with GRID treatment, which is common in patients receiving GRID treatment, makes it difficult to interpret the result. Such findings require carefully controlled trials for further validation.

There are several reports of clinical application of the SFRT in the treatment of patients with advanced and bulky tumors. The main outcomes from some of the block-based GRID studies have been summarized by Billena et $\mathrm{al}^{58}$. We also highlighted some of the most important findings from the other studies, including block-based and MLC-based GRID therapy as well as lattice radiotherapy in Table 2.

Taken together, the data suggest the potential biological benefits of SFRT for the treatment of different tumor types with excellent tumor control and minimal serious acute or late toxicity compared to conventional treatment modalities. While the results are promising, the clinical use of SFRT is limited to relatively few centers. Still, there are many issues that need to be resolved before GRID therapy can be widely used as a standard treatment modality in the clinic. Current clinical studies have some limitations to accurately address these issues. To move forward with routine clinical implementation of SFRT, clear and accepted standards must be introduced for accurate selection of patients or tumors which are suitable for SFRT. Furthermore, there is a need for a recommendation for the physical geometries and dose distribution, dosing, and regimens schedules. The lack of uniformity in dosimetric characteristics (prescribed dose, hole size and hole separation, open to close field ratio, the shape of the holes, valley to peak dose ratio and subsequent conventional EBRT regimen) and the delivery time, as well as heterogeneity in the study population in terms of tumor site and histology in available clinical studies, make interpreting the data difficult. In this context, more biological investigations using animal models as well as phase 1 and 2 trials are urgently needed to elucidate the relationship between the treatment response and clinical and dosimetric parameters. Another major limitation that reduces the validity of trial results is the lack of a control arm. While there are several clinical investigations, none of them presents comparative data between GRID therapy and conventional radiation therapy. 
Table 2. Clinical results of spatially fractionated radiation therapy $\mathbf{1}^{11,24,25,47,59-63}$

\begin{tabular}{|c|c|c|c|c|c|c|c|c|}
\hline Reference & Histology/site & Method & $\begin{array}{c}\text { Pt\# } \\
\text { (Sites) }\end{array}$ & $\begin{array}{c}\text { Tumor } \\
\text { dimension }\end{array}$ & $\begin{array}{c}\text { Dose of SFRT } \\
(\mathrm{Gy})\end{array}$ & $\begin{array}{c}\text { Other } \\
\text { treatment }\end{array}$ & Tumor Response & Side effects \\
\hline $2002^{11}$ & $\begin{array}{l}\text { abdomen \& } \\
\text { pelvis, } \mathrm{H} \& \mathrm{~N}, \\
\text { thorax, } \\
\text { extremities }\end{array}$ & $\begin{array}{l}\text { Block- } \\
\text { based }\end{array}$ & $308(357)$ & $>8 \mathrm{~cm}$ & $10-20$ & $\begin{array}{l}\text { Surgery } \\
(25 \%) \\
\& \text { EBRT } \\
(73 \%)\end{array}$ & $\begin{array}{l}73 \% \text { response rate } \\
(\text { GRID only) } \\
95 \% \text { response rate } \\
(\text { GRID \& EBRT) }\end{array}$ & $\begin{array}{l}\text { No late grade } 3 \text { skin, } \\
\text { subcutaneous, mucosal } \\
\text { or other toxicity }\end{array}$ \\
\hline $2002^{47}$ & $\begin{array}{l}\mathrm{H} \& \mathrm{~N} \text {, extremity, } \\
\text { abdomen \& pelvis } \\
\text { and other }\end{array}$ & $\begin{array}{l}\text { Block- } \\
\text { based }\end{array}$ & $34(37)$ & $>8 \mathrm{~cm}$ & $12-20$ & $\begin{array}{l}\text { EBRT } \\
(100 \%)\end{array}$ & $\begin{array}{l}81 \% \text { overall response } \\
(32 \% \text { CR \& } 49 \% \text { PR) }\end{array}$ & - \\
\hline $2004^{59}$ & $\begin{array}{l}\text { Soft tissue } \\
\text { sarcomas } \\
\text { (abdomen, pelvis, } \\
\text { extremity, H\&N, } \\
\text { chest wall, spine) }\end{array}$ & $\begin{array}{l}\text { Block- } \\
\text { based }\end{array}$ & 37 & $>10 \mathrm{~cm}$ & $12-20$ & $\begin{array}{l}\text { CT }(35 \%) \\
\& \text { EBRT } \\
(100 \%)\end{array}$ & $\begin{array}{c}100 \% \text { response rate } \\
\text { (cohort } 1=\text { surgical resection } \\
\text { following SFR \& EBRT) } \\
71 \% \text { response rate } \\
\text { (cohort } 2=\text { SFRT \& EBRT } \\
\text { with no surgical resection) }\end{array}$ & $\begin{array}{c}\text { Cohort 1: two grade } 4 \text { skin } \\
\text { reactions and three delayed } \\
\text { wound healing } \\
\text { Cohort } 2 \text { : Nine patients survived } \\
\text { less than } 6 \text { months, } 7 \text { survived } \\
6-12 \text { months and } 3 \text { survived } \\
\text { beyond } 1 \text { year }\end{array}$ \\
\hline $2008^{60}$ & $\begin{array}{l}\text { Non-small cell } \\
\text { lung carcinoma }\end{array}$ & $\begin{array}{l}\text { Block- } \\
\text { based }\end{array}$ & 10 & $>6 \mathrm{~cm}$ & 15 & $\begin{array}{l}\text { EBRT } \\
(100 \%)\end{array}$ & $\begin{array}{c}100 \% \text { overall response } \\
(71.4 \% \text { CR \& } 28.5 \% \mathrm{PR})\end{array}$ & $\begin{array}{l}\text { No grade } 3 / 4 \text { acute toxicities } \\
\text { Two grade } 2 \text { lung toxicity with } \\
\text { moderate symptomatic fibrosis } \\
\text { No other late effects }\end{array}$ \\
\hline $2010^{24}$ & $\begin{array}{l}\text { Advanced } \\
\text { carcinoma of the } \\
\text { cervix and bulky } \\
\text { pelvic mass }\end{array}$ & LRT & $\begin{array}{l}1 \text { case } \\
\text { report }\end{array}$ & $\begin{array}{l}\text { Volume: } \\
250 \mathrm{cc}\end{array}$ & $\begin{array}{l}24 \mathrm{~Gy} / \mathrm{Fr} \\
\text { to vertices } \\
\text { and } 1.8 \mathrm{~Gy} / \mathrm{Fr} \\
\text { to peripheral }\end{array}$ & CT \& EBRT & $\begin{array}{c}\text { Clinical pathological CR } \\
\text { with cessation of vaginal } \\
\text { bleeding and absence of } \\
\text { a palpable mass on pelvic } \\
\text { exam }\end{array}$ & $\begin{array}{l}\text { Acute toxicity: was limited } \\
\text { to diarrhea }\end{array}$ \\
\hline $2015^{61}$ & $\begin{array}{l}\text { Large metastatic } \\
\text { mass from ovarian } \\
\text { carcinosarcoma }\end{array}$ & LRT & $\begin{array}{l}1 \text { case } \\
\text { report }\end{array}$ & $>14 \mathrm{~cm}$ & $\begin{array}{l}9 \mathrm{~Gy} / \mathrm{Fr} \\
\text { to vertices } \\
\text { and } 3 \mathrm{~Gy} / \mathrm{Fr} \\
\text { to peripheral }\end{array}$ & CT \& EBRT & $100 \% \mathrm{CR}$ & Without any significant toxicity \\
\hline $2018^{25}$ & $\begin{array}{l}\text { Non-small cell } \\
\text { lung cancer }\end{array}$ & LRT & $\begin{array}{l}1 \text { case } \\
\text { report }\end{array}$ & $7.5 \mathrm{~cm}$ & $\begin{array}{l}18 \mathrm{~Gy} \\
\text { to vertices } \\
\text { and } 3 \mathrm{~Gy} \\
\text { to peripheral }\end{array}$ & CT \& EBRT & $100 \% \mathrm{CR}$ & $\begin{array}{l}\text { The patient was asymptomatic } \\
\text { (in a six-month follow-up) }\end{array}$ \\
\hline $2019^{62}$ & $\begin{array}{l}\text { Non-small cell } \\
\text { lung cancer }\end{array}$ & LRT & 10 & $\begin{array}{l}5-14 \mathrm{~cm} \\
(\text { mean: } \\
8 \mathrm{~cm})\end{array}$ & $\begin{array}{c}18 \text { Gy to } \\
\text { vertices and } 3 \\
\text { Gy to peripheral }\end{array}$ & $\begin{array}{l}\text { EBRT } \\
(100 \%)\end{array}$ & $\begin{array}{l}\text { Decrease in tumor volume: } \\
442 \% \\
\text { The range of overall } \\
\text { survival: } 4-86 \text { months } \\
\text { (mean 22) }\end{array}$ & $\begin{array}{l}\text { No mortality related to LRT } \\
\text { No significant acute or chronic } \\
\text { toxicity }\end{array}$ \\
\hline $2019^{63}$ & $\begin{array}{c}\text { Diverse } \\
\text { (most commonly } \\
\text { SCC of } \mathrm{H} \& \mathrm{~N})\end{array}$ & $\begin{array}{l}\text { MLC- } \\
\text { based \& } \\
\text { block- } \\
\text { based }\end{array}$ & 21 & $5-25 \mathrm{~cm}$ & $15-20$ & $\begin{array}{l}\text { CT }(57 \%) \\
\& \text { EBRT } \\
(100 \%)\end{array}$ & $\begin{array}{l}54.4 \% \text { palliative response } \\
\qquad(6 / 11) \\
44.4 \% \text { curative CR }(4 / 9)\end{array}$ & $\begin{array}{l}\text { Five grade } 3 \text { or } 4 \text { skin toxicity } \\
\text { No grade } 3 \text { or higher mucous } \\
\text { membrane toxicities } \\
\text { Late toxicities: are not reported }\end{array}$ \\
\hline
\end{tabular}

Abbreviations: $H \& N=$ head \& neck; SCC = squamous cell carcinoma; EBRT = External beam radiation therapy; SFR = Spatially fractionated radiation therapy; LRT $=$ LATTICE radiotherapy; $M L C=$ Multi-leaf collimator, $C T=$ Chemotherapy; $C R=$ Complete response $; P R=P$ artial response, Fr $=$ Fraction, Pt\# = Number of patients

\section{Therapeutic ratio and radiobiological modeling}

Several methods and models have been developed recently as an attempt to put the SFRT on firmer theoretical ground. To illustrate the biological efficacy of the nonhomogeneous dose distributions, Niemierko ${ }^{64}$ introduced a new concept of equivalent uniform dose (EUD), based on the linear-quadratic (LQ) model. Later, Zwicker et $\mathrm{al}^{13}$ extended this model and introduced the concept of therapeutic ratio (TR) as the ratio of the normal cell survival fraction under GRID field to that predicted in the open field. Afterwards, most of the GRID studies used the concept of TR to evaluate the biological advantage of GRID therapy quantitatively. These studies show that the therapeutic ratio may be affected by various factors, such as tissue motion, design of the GRID blocks, delivered dose, radiosensitivity of the cell population, size and location of tumors, delivery methods, and spatial modulation of the SFRT field ${ }^{13,65-67}$ However, our current understanding of the precise role of each factor in determining therapeutic ratio is still poor and is limited to the results of a few simulation studies.

In recent years, the suitability of the LQ model for evaluating cell killing at a large single fraction dose, such that used in GRID therapy has been questioned, and several models have been proposed in an effort to match the LQ model with high dose regimens. ${ }^{68,69}$ Zhang et al ${ }^{66}$ calculated the TR for melanoma cell lines using a modified LQ (MLQ) model that was introduced for 
the high-dose range. They showed that the difference between LQ and MLQ models is minimal and both can be used to calculate EUD and TR. The same results have been reported by Gholami et al. for different tumor cell lines and various prescribed doses. ${ }^{65}$ Nevertheless, both of these studies are based on the simulation, and their predictions have not been validated in-vitro.

Furthermore, experimental data show that the survival in spatially modulated radiation fields differs significantly from that of predicted using the LQ model. ${ }^{70}$ The cell-specific parameters of the conventional LQ model are obtained from conventional open fields and do not incorporate bystander effects. Although it has been shown that the bystander effects may play an important role in cell survival in the modulated field. ${ }^{71,72}$ To address this, Peng et $\mathrm{al}^{73}$ developed an extended LQ model with an additional bystander signaling parameter describing the cell signaling effects, to calculate cell SFs after MLC-based GRID irradiation. They showed that their extended model has the ability to accurately predict the SF following GRID therapy and gives more reliable results than the conventional LQ model. ${ }^{73}$ In another study, McMahon et $\mathrm{al}^{74}$ presented a summary of the shortcomings of former bystander models and introduced a more robust and generalized model that incorporates signal production and response kinetics along with the effects of direct irradiation. This model could accurately predict the SF of cells in modulated fields. In 2017, Butterworth et $\mathrm{al}^{75}$ used this model to evaluate the impact of bystander signals on dose-volume histograms and EUD for a range of different GRID treatment plans. They concluded that incorporation of the intercellular signalling effect in the radiobiological model leads to the reduction in survival fraction within the low-dose region of GRID field and results in an increase in the EUD across the tumor. These works indicate that the conventional LQ models oversimplify dose-response relation and are not suitable for evaluating GRID outcome.

\section{Conclusion}

While several patients have been treated by the SFRT technique so far, its routine clinical use has limited to relatively few radiotherapy centers, most commonly for palliative intent. However, many reasons could be attributed to this, but among the major ones are: the lack of the equipment, the technical challenges related to each method of SFRT; lack of standard protocols for selection of the patient, optimal physical geometries and dosimetric parameters; as well as poor knowledge about the secondary effects and the biological mechanisms behind the success of this technique (though some radiobiological mechanisms and model have been suggested recently).

Altogether, preliminary data suggest that SFRT is a safe and effective tool for treating bulky or radio-resistant tumors, although high-level evidence is currently lacking. To move forward with routine clinical implementation of SFRT, more investigations are needed to clarify the radiobiological mechanism of SFRT and to determine ideal dosimetric parameters to introduce a reference protocol for the future application of the SFRT.

\section{Acknowledgments}

This work is a part of $\mathrm{PhD}$ thesis (No: 399019) which was financially supported by the Isfahan University of Medical Sciences, Isfahan, Iran.

\section{References}

1. Tao L, Rakfal S, Wu A. Comparison of integral doses in conventional 2D, conformal 3D and IMRT plans. Medical Physics. 2002;29(6):1211.

2. Arabpour A, Shahbazi-Gahrouei D. Effect of Hypofractionation on Prostate Cancer Radiotherapy. International Journal of Cancer Management. 2017;10(10):e12204. https://doi.org/10.5812/ijcm.12204

3. Shahbazi-Gahrouei D, Gookizadeh A, Sohrabi M, Arab Z. Normal tissues absorbed dose and associated risk in breast radiotherapy. Journal of Radiobiology. 2015;2(1).

4. Peñagarícano JA, Moros EG, Ratanatharathorn V, Yan Y, Corry P. Evaluation of spatially fractionated radiotherapy (GRID) and definitive chemoradiotherapy with curative intent for locally advanced squamous cell carcinoma of the head and neck: initial response rates and toxicity. Int J Radiat Oncol Biol Phys. 2010;76(5):1369-1375. https://doi.org/10.1016/j.ijrobp.2009.03.030

5. Kaiser A, Mohiuddin MM, Jackson GL. Dramatic response from neoadjuvant, spatially fractionated GRID radiotherapy (SFGRT) for large, high-grade extremity sarcoma. Journal of Radiation Oncology. 2013;2(1):103-106. https://doi.org/10.1007/s13566-012-0064-5

6. Asur R, Butterworth KT, Penagaricano JA, Prise KM, Griffin RJ. High dose bystander effects in spatially fractionated radiation therapy. Cancer Letters. 2015;356(1):52-57. https://doi.org/10.1016/j.canlet.2013.10.032

7. Mohiuddin M, Fujita M, Regine WF, Megooni AS, Ibbott GS, Ahmed MM. High-dose spatially-fractionated radiation (GRID): a new paradigm in the management of advanced cancers. Int J Radiat Oncol Biol Phys. 1999;45(3):721-727. https://doi.org/10.1016/S03603016(99)00170-4 
8. Saeb M, Shahbazi-Gahrouei D, Monadi S. Evaluation of targeted image-guided radiation therapy treatment planning system by use of american association of physicists in medicine task group-119 test cases. Journal of Medical Signals and Sensors. 2018;8(2):95. https://doi.org/10.4103/jmss.JMSS_44_17

9. Mohiuddin M, Curtis DL, Grizos WT, Komarnicky L. Palliative treatment of advanced cancer using multiple nonconfluent pencil beam radiation: A pilot study. Cancer. 1990;66(1):114-118. https://doi.org/10.1002/1097-0142(19900701)66:1<114::AIDCNCR2820660121>3.0.CO;2-L

10. Mohiuddin M, Stevens JH, Reiff JE, Huq MS, Suntharalingam N. Spatially fractionated (GRID) radiation for palliative treatment of advanced cancer. Radiation Oncology Investigations. 1996;4(1):41-47. https://doi.org/10.1002/(SICI)1520-6823(1996)4:1<41::AIDROI7>3.0.CO;2-M

11. Mohiuddin M, Kudrimoti M, Regine W, Meigooni A, Zwicker R. Spatially fractionated radiation (SFR) in the management of advanced cancer. Int J Radiat Oncol Biol Phys. 2002;54:342-343. https://doi.org/10.1016/S0360-3016(02)03646-5

12. Meigooni A, Malik U, Zhang H, et al. Grid: A location dependent intensity modulated radiotherapy for bulky tumors. Iranian Journal of Radiation Research (Print). 2005;2(4):167-174.

13. Zwicker RD, Meigooni A, Mohiuddin M. Therapeutic advantage of grid irradiation for large single fractions. Int J Radiat Oncol Biol Phys. 2004;58(4):1309-1315. https://doi.org/10.1016/j.ijrobp.2003.07.003

14. Buckey C, Stathakis S, Cashon K, et al. Evaluation of a commercially-available block for spatially fractionated radiation therapy. Journal of Applied Clinical Medical Physics. 2010;11(3). https://doi.org/10.1120/jacmp.v11i3.3163

15. Ha JK, Zhang G, Naqvi SA, Regine WF, Cedric XY. Feasibility of delivering grid therapy using a multileaf collimator. Medical Physics. 2006;33(1):76-82. https://doi.org/10.1118/1.2140116

16. Neuner G, Mohiuddin MM, Vander Walde N, et al. High-dose spatially fractionated GRID radiation therapy (SFGRT): a comparison of treatment outcomes with Cerrobend vs. MLC SFGRT. Int J Radiat Oncol Biol Phys. 2012;82(5):1642-1649. https://doi.org/10.1016/j.ijrobp.2011.01.065

17. Cole AJ, McGarry CK, Butterworth KT, et al. Investigating the influence of respiratory motion on the radiation induced bystander effect in modulated radiotherapy. Physics in Medicine \& Biology. 2013;58(23):8311. https://doi.org/10.1088/0031-9155/58/23/8311

18. Jordan K, Francis W, Dar A, Yu E, Yartsev S, Chen J. SU-C-BRA-01: Efficient Generation of Beamlet Arrays with Hybrid Multileaf Collimator for Grid Therapy. Medical Physics. 2011;38(6Part2):3368-3368. https://doi.org/10.1118/1.3611461

19. Almendral P, Mancha PJ, Roberto D. Feasibility of a simple method of hybrid collimation for megavoltage grid therapy. Medical Physics. 2013;40(5):051712. https://doi.org/10.1118/1.4801902

20. Zhang X, Penagaricano J, Yan Y, et al. Spatially fractionated radiotherapy (GRID) using helical tomotherapy. Journal of Applied Clinical Medical Physics. 2016;17(1). https://doi.org/10.1120/jacmp.v17i1.5934

21. Zhang X, Penagaricano J, Yan Y, et al. Application of spatially fractionated radiation (GRID) to helical tomotherapy using a novel TOMOGRID template. Technology in Cancer Research \& Treatment. 2016;15(1):91-100. https://doi.org/10.7785/tcrtexpress.2013.600261

22. Narayanasamy G, Zhang X, Meigooni A, et al. Therapeutic benefits in grid irradiation on Tomotherapy for bulky, radiation-resistant tumors. Acta Oncologica. 2017;56(8):1043-1047. https://doi.org/10.1080/0284186X.2017.1299219

23. Wu X, Wright J, Gupta S, Pollack A. On modern technical approaches of three-dimensional high-dose lattice radiotherapy (LRT). Cureus. 2010;2(3). https://doi.org/10.7759/cureus.9

24. Amendola BE, Perez N, Wu X, et al. Lattice radiotherapy with rapidarc for treatment of gynecological tumors: dosimetric and early clinical evaluations. Cureus. 2010;2(9). https://doi.org/10.7759/cureus.15

25. Amendola BE, Perez NC, Wu X, Suarez JMB, Lu JJ, Amendola M. Improved outcome of treating locally advanced lung cancer with the use of Lattice Radiotherapy (LRT): A case report. Clinical and Translational Radiation Oncology. 2018;9:68-71. https://doi.org/10.1016/j.ctro.2018.01.003

26. Jin J-Y, Zhao B, Kaminski JM, et al. A MLC-based inversely optimized 3D spatially fractionated grid radiotherapy technique. Radiotherapy and Oncology. 2015;117(3):483-486. https://doi.org/10.1016/j.radonc.2015.07.047

27. Schültke E, Balosso J, Breslin T, et al. Microbeam radiation therapy-grid therapy and beyond: a clinical perspective. The British Journal of Radiology. 2017;90(1078):20170073. https://doi.org/10.1259/bjr.20170073

28. Slatkin DN, Spanne P, Dilmanian F, Sandborg M. Microbeam radiation therapy. Medical Physics. 1992;19(6):1395-1400. https://doi.org/10.1118/1.596771

29. Grotzer M, Schültke E, Bräuer-Krisch E, Laissue J. Microbeam radiation therapy: clinical perspectives. Physica Medica. 2015;31(6):564-567. https://doi.org/10.1016/j.ejmp.2015.02.011

30. Slatkin D, Spanne P, Dilmanian F, Gebbers J, Laissue J. Subacute neuropathological effects of microplanar beams of x-rays from a synchrotron wiggler. Proceedings of the National Academy of Sciences. 1995;92(19):8783-8787. https://doi.org/10.1073/pnas.92.19.8783 
31. Keivan H, Shahbazi-Gahrouei D, Shanei A, Amouheidari A. Assessment of imprecise small photon beam modeling by two treatment planning system Algorithms. Journal of Medical Signals and Sensors. 2018;8(1):39. https://doi.org/10.4103/jmss.JMSS_28_17

32. Keivan H, Shahbazi-Gahrouei D, Shanei A. Evaluation of dosimetric characteristics of diodes and ionization chambers in small megavoltage photon field dosimetry. International Journal of Radiation Research. 2018;16(3):311-321.

33. Wu X, Ahmed M, Pollack A. On modern technical approaches of 3D high-dose lattice radiotherapy (LRT). Int J Radiat Oncol Biol Phys. 2009;75(3):S723. https://doi.org/10.1016/j.ijrobp.2009.07.1647

34. Nobah A, Mohiuddin M, Devic S, Moftah B. Effective spatially fractionated GRID radiation treatment planning for a passive grid block. The British Journal of Radiology. 2015;88(1045):20140363. https://doi.org/10.1259/bjr.20140363

35. Costlow HN, Zhang H, Das IJ. A treatment planning approach to spatially fractionated megavoltage grid therapy for bulky lung cancer. Medical Dosimetry. 2014;39(3):218-226. https://doi.org/10.1016/j.meddos.2014.02.004

36. Chegeni N, Karimi AH, Jabbari I, Arvandi S. Photoneutron dose estimation in GRID therapy using an anthropomorphic phantom: A monte carlo study. Journal of Medical Signals and Sensors. 2018;8(3):175. https://doi.org/10.4103/jmss.JMSS_13_18

37. Wang X, Charlton MA, Esquivel C, Eng TY, Li Y, Papanikolaou N. Measurement of neutron dose equivalent outside and inside of the treatment vault of GRID therapy. Medical Physics. 2013;40(9):093901. https://doi.org/10.1118/1.4816653

38. Karimi AH, Brkić H, Shahbazi-Gahrouei D, Haghighi SB, Jabbari I. Essential considerations for accurate evaluation of photoneutron contamination in Radiotherapy. Applied Radiation and Isotopes. 2019;145:24-31. https://doi.org/10.1016/j.apradiso.2018.12.007

39. Khosravi M, Shahbazi-Gahrouei D, Jabbari K, et al. Photoneutron contamination from an 18 MV Saturne medical linear accelerator in the treatment room. Radiation Protection Dosimetry. 2013;156(3):356-363. https://doi.org/10.1093/rpd/nct078

40. Tajiki S, Gholami S, Esfahani M, et al. Photon and photon-neutron experimental dosimetry in Grid therapy with $18 \mathrm{MV}$ photon beams. Journal of Radiotherapy in Practice.1-7. https://doi.org/10.1017/S1460396920000655

41. Hopewell JW, Trott K-R. Volume effects in radiobiology as applied to radiotherapy. Radiotherapy and Oncology. 2000;56(3):283288. https://doi.org/10.1016/S0167-8140(00)00236-X

42. Marks H. Clinical experience with irradiation through a GRID. Radiology. 1952;58(3):338-342. https://doi.org/10.1148/58.3.338

43. Reiff JE, Huq MS, Mohiuddin M, Suntharalingam N. Dosimetric properties of megavoltage grid therapy. Int J Radiat Oncol Biol Phys. 1995;33(4):937-942. https://doi.org/10.1016/0360-3016(95)00114-3

44. Huhn JL, Regine WF, Valentino JP, Meigooni AS, Kudrimoti M, Mohiuddin M. Spatially fractionated GRID radiation treatment of advanced neck disease associated with head and neck cancer. Technology in Cancer Research \& Treatment. 2006;5(6):607-612. https://doi.org/10.1177/153303460600500608

45. Asur RS, Sharma S, Chang C-W, et al. Spatially fractionated radiation induces cytotoxicity and changes in gene expression in bystander and radiation adjacent murine carcinoma cells. Radiation Research. 2012;177(6):751-765. https://doi.org/10.1667/RR2780.1

46. Mothersill C, Rusin A, Fernandez-Palomo C, Seymour C. History of bystander effects research 1905-present; what is in a name? International Journal of Radiation Biology. 2018;94(8):696-707. https://doi.org/10.1080/09553002.2017.1398436

47. Sathishkumar S, Dey S, Meigooni AS, et al. The impact of TNF- $\alpha$ induction on therapeutic efficacy following high dose spatially fractionated (GRID) radiation. Technology in Cancer Research \& Treatment. 2002;1(2):141-147. https://doi.org/10.1177/153303460200100207

48. Desai S, Kobayashi A, Konishi T, Oikawa M, Pandey BN. Damaging and protective bystander cross-talk between human lung cancer and normal cells after proton microbeam irradiation. Mutation Research/Fundamental and Molecular Mechanisms of Mutagenesis. 2014;763:39-44. https://doi.org/10.1016/j.mrfmmm.2014.03.004

49. Sathishkumar S, Boyanovski B, Karakashian A, et al. Elevated sphingomyelinase activity and ceramide concentration in serum of patients undergoing high dose spatially fractionated radiation treatment: implications for endothelial apoptosis. Cancer Biology \& Therapy. 2005;4(9):979-986. https://doi.org/10.4161/cbt.4.9.1915

50. Kanagavelu S, Gupta S, Wu X, et al. In vivo effects of lattice radiation therapy on local and distant lung cancer: potential role of immunomodulation. Radiat Res. 2014;182(2):149-162. https://doi.org/10.1667/RR3819.1

51. Manda K, Glasow A, Paape D, Hildebrandt G. Effects of ionizing radiation on the immune system with special emphasis on the interaction of dendritic and T cells. Frontiers in Oncology. 2012;2:102. https://doi.org/10.3389/fonc.2012.00102

52. Lugade AA, Moran JP, Gerber SA, Rose RC, Frelinger JG, Lord EM. Local radiation therapy of B16 melanoma tumors increases the generation of tumor antigen-specific effector cells that traffic to the tumor. The Journal of Immunology. 2005;174(12):7516-7523. https://doi.org/10.4049/jimmunol.174.12.7516

53. Lee Y, Auh SL, Wang Y, et al. Therapeutic effects of ablative radiation on local tumor require CD8+ T cells: changing strategies for cancer treatment. Blood. 2009;114(3):589-595. https://doi.org/10.1182/blood-2009-02-206870

54. Edwards J, Shah P, Huhn J, et al. Definitive GRID and fractionated radiation in bulky head and neck cancer associated with low rates of distant metastasis. Int J Radiat Oncol Biol Phys. 2015;93(3):E334. https://doi.org/10.1016/j.ijrobp.2015.07.1399 
55. Gupta S, Zagurovskaya M, Wu X, Sathishkumar S, Awan S, Mohiuddin M. Spatially Fractionated Grid High-dose radiation-induced tumor regression in A549 lung adenocarcinoma xenografts: cytokines and ceramide regulators balance in abscopal phenomena. Sylvester Comprehensive Cancer Center. 2014;20.

56. Griffin RJ, Koonce NA, Dings RPM, et al. Microbeam radiation therapy alters vascular architecture and tumor oxygenation and is enhanced by a galectin-1 targeted anti-angiogenic peptide. Radiation Research. 2012;177(6):804-812. https://doi.org/10.1667/RR2784.1

57. Peters ME, Shareef MM, Gupta S, et al. Potential utilization of bystander/abscopal-mediated signal transduction events in the treatment of solid tumors. Current Signal Transduction Therapy. 2007;2(2):129-143. https://doi.org/10.2174/157436207780619509

58. Billena C, Khan AJ. A current review of spatial fractionation: back to the future? Int J Radiat Oncol Biol Phys. 2019;104(1):177-187. https://doi.org/10.1016/j.ijrobp.2019.01.073

59. Kudrimoti M, Mohiuddin M, Ahmed M, et al. Use of high dose spatially fractionated radiation (GRID therapy) in management of large, poor prognostic stage III (> 10cms) soft tissue sarcomas. Int J Radiat Oncol Biol Phys. 2004;60(1):S575. https://doi.org/10.1016/j.ijrobp.2004.07.564

60. Somaiah N, Warrington J, Taylor H, Ahmad R, Tait D, Glees J. High dose spatially fractionated radiotherapy (SFR) using a megavoltage GRID in advanced lung tumors: Preliminary experience in UK. Int J Radiat Oncol Biol Phys. 2008;72(1):S490. https://doi.org/10.1016/j.ijrobp.2008.06.1439

61. Suarez JMB, Amendola BE, Perez N, Amendola M, Wu X. The use of lattice radiation therapy (LRT) in the treatment of bulky tumors: a case report of a large metastatic mixed Mullerian ovarian tumor. Cureus. 2015;7(11).

62. Amendola BE, Perez NC, Wu X, Amendola MA, Qureshi IZ. Safety and efficacy of lattice radiotherapy in voluminous non-small cell lung cancer. Cureus. 2019;11(3). https://doi.org/10.7759/cureus.4263

63. Choi JI, Daniels J, Cohen D, Li Y, Ha CS, Eng TY. Clinical Outcomes of Spatially Fractionated GRID Radiotherapy in the Treatment of Bulky Tumors of the Head and Neck. Cureus. 2019;11(5). https://doi.org/10.7759/cureus.4637

64. Niemierko A. Reporting and analyzing dose distributions: a concept of equivalent uniform dose. Medical Physics. 1997;24(1):103110. https://doi.org/10.1118/1.598063

65. Gholami S, Nedaie HA, Longo F, Ay MR, Wright S, Meigooni AS. Is grid therapy useful for all tumors and every grid block design? Journal of Applied Clinical Medical Physics. 2016;17(2). https://doi.org/10.1120/jacmp.v17i2.6015

66. Zhang H, Zhong H, Barth RF, Cao M, Das IJ. Impact of dose size in single fraction spatially fractionated (grid) radiotherapy for melanoma. Medical physics. 2014;41(2):021727. https://doi.org/10.1118/1.4862837

67. Naqvi SA, Mohiuddin MM, Ha JK, Regine WF. Effects of tumor motion in GRID therapy. Medical physics. 2008;35(10):4435-4442. https://doi.org/10.1118/1.2977538

68. Guerrero M, Li XA. Extending the linear-quadratic model for large fraction doses pertinent to stereotactic radiotherapy. Physics in Medicine \& Biology. 2004;49(20):4825. https://doi.org/10.1088/0031-9155/49/20/012

69. Ekstrand KE. The Hug-Kellerer equation as the universal cell survival curve. Physics in Medicine \& Biology. 2010;55(10):N267. https://doi.org/10.1088/0031-9155/55/10/N01

70. Suchowerska N, Ebert MA, Zhang M, Jackson M. In vitro response of tumour cells to non-uniform irradiation. Physics in Medicine \& Biology. 2005;50(13):3041. https://doi.org/10.1088/0031-9155/50/13/005

71. Butterworth KT, McGarry CK, Trainor C, O'Sullivan JM, Hounsell AR, Prise KM. Out-of-field cell survival following exposure to intensity-modulated radiation fields. Int J Radiat Oncol Biol Phys. 2011;79(5):1516-1522. https://doi.org/10.1016/j.ijrobp.2010.11.034

72. Butterworth KT, McGarry CK, Trainor C, et al. Dose, dose-rate and field size effects on cell survival following exposure to nonuniform radiation fields. Physics in Medicine \& Biology. 2012;57(10):3197. https://doi.org/10.1088/0031-9155/57/10/3197

73. Peng V, Suchowerska N, Rogers L, Claridge Mackonis E, Oakes S, McKenzie DR. Grid therapy using high definition multileaf collimators: realizing benefits of the bystander effect. Acta Oncologica. 2017;56(8):1048-1059. https://doi.org/10.1080/0284186X.2017.1299939

74. McMahon SJ, Butterworth KT, Trainor C, et al. A kinetic-based model of radiation-induced intercellular signalling. PloS one. 2013;8(1):e54526. https://doi.org/10.1371/journal.pone.0054526

75. Butterworth KT, Ghita M, McMahon SJ, et al. Modelling responses to spatially fractionated radiation fields using preclinical imageguided radiotherapy. The British Journal of Radiology. 2017;90(1069):20160485. https://doi.org/10.1259/bjr.20160485 